Efektor, Volume 7 Issue 1, 2020, Pages 73 - 79

Available online at: http://ojs.unpkediri.ac.id/index.php/efektor-e

DOI: https://doi.org/10.29407/e.v7i1.14364

\title{
Analisis Butir Soal Matematika UN SMP/MTs Tahun 2018/2019 Ditinjau dari Kriteria Koneksi Matematis
}

\author{
Habib Hasbullah \\ habib_hasbullah@gmail.com \\ MTs Negeri 2 Trenggalek
}

\begin{abstract}
Mathematical connection ability is one of the abilities students must have in learning mathematics. The importance of mathematical connection ability is inseparable from the characteristics of mathematics which is a hierarchically structured science and interrelated between one concept with another concept. In addition to the relationship between concepts in mathematics, aspects of mathematical connections also contain connections between mathematical concepts and other fields of science and the relationship between mathematics and everyday life. Considering the importance of the ability of these mathematical connections, mathematical connection questions are also included in the National Mathematics Examination at various levels. This study examines the components of the Mathematics National Examination items that meet the mathematical connection criteria. The objectives of this study are: a) to find out the percentage of School Exam questions that meet the mathematical connection criteria, b) find out examples of School Exam questions that meet the mathematical connection criteria. The results of this study indicate that $80 \%$ of school exam questions meet the mathematical connection criteria.
\end{abstract}

Keywords: mathematical connections, question analysis, national exams

Abstrak

Kemampuan koneksi matematis merupakan salah satu kemampuan yang harus dikuasai siswa dalam belajar matematika. Pentingnya kemampuan koneksi matematis tidak terlepas dari karakteristik matematika yang merupakan ilmu yang tersusun secara hierarkhis dan saling terkait antara konsep yang satu dengan konsep lainnya. Selain keterkaitan antar konsep dalam matematika, aspek koneksi matematis juga memuat adanya koneksi antara konsep matematika dengan bidang ilmu lain dan keterkaitan antara matematika dengan kehidupan sehari-hari. Mengingat pentingnya kemampuan koneksi matematis tersebut, soal koneksi matematis juga termasuk dalam Ujian Nasional Matematika dalam berbagai jenjang. Penelitian ini mengkaji tentang komponen butir soal Ujian Nasional Matematika yang memenuhi kriteria koneksi matematis. Tujuan penelitian ini adalah: a) untuk mengetahui prosentase soal Ujian Sekolah yang memenuhi kriteria koneksi matematis, b) mengetahui contoh soal Ujian Sekolah yang memenuhi kriteria koneksi matematis. Hasil penelitian ini menunjukkan bahwa $80 \%$ soal Ujian Sekolah memenuhi kriteria koneksi matematis.

Kata Kunci: koneksi matematis, analisis soal, ujian nasional.

\section{PENDAHULUAN}

Salah satu kemampuan yang perlu dikuasai siswa dalam belajar matematika adalah kemampuan koneksi matematis. Sumarmo (2013) menyatakan bahwa kemampuan koneksi matematis merupakan salah satu kemampuan yang penting untuk dikuasai siswa. Hal ini dikarenakan ketika siswa telah mampu mengaitkan antar konsep atau beberapa ide matematika, maka ia akan memperoleh pemahaman yang lebih dalam dan baik tentang materi tersebut. Koneksi matematis (Mathematical Connections) mencakup kemampuan dasar untuk mengaitkan hubungan antar konsep dalam matematika, hubungan antara konsep matematika dengan ilmu lain dan juga kemampuan untuk mengaplikasikan konsep matematika dalam penyelesaian masalah nyata. Dalam belajar matematika, siswa hendaknya memahami konteks antar ide-ide dalam matematika dan antara ide matematika dengan bidang ilmu lainnya. Tujuan belajar matematika di sekolah adalah: 1) untuk memahami konsep serta keterampilan matematika yang dapat diaplikasikan dalam kehidupan sehari-hari dan dengan disiplin ilmu yang 


\section{Efektor, Volume 7 Issue 1, 2020, Pages 73 - 79}

Habib Hasbullah

terkait, 2) dapat mengenali serta menggunakan ide-ide matematika serta antara matematika dan disiplin ilmu yang lainnya (Toh, 2012).

Badjeber (2017) mengungkapkan bahwa koneksi merupakan suatu hubungan atau keterkaitan dari beberapa unsur. Dalam pembelajaran matematika, unsur-unsur yang dimaksudkan tersebut dapat berupa konsep, prinsip ataupun prosedur. Sumarmo (2013) menyatakan bahwa kemampuan koneksi matematis madalah kemampuan mengaitkan konsep, prinsip atau prosedur matematika dengan matematika itu sendiri, dengan bidang ilmu lain serta dengan kehidupan sehari-hari. Menguasai kemampuan koneksi matematik (Mathematical Connections) artinya siswa memnpunyai kemampuan dasar mengaplikasikan konsep matematika dalam penyelesaian masalah nyata. Apabila ditinjau dari kurikulum matematika sekoeksi, kemampuan siswa untuk memahami koneksi antar konsep dalam matematika maupun koneksi antara konsep matematika dengan disiplin ilmu lainnya merupakan bagian penting. Oleh karena itu, guru hendakanya memfasilitasi dan memberikan kesempatan belajar kepada siswa agar mempunyai pengalaman belajar dalam mengkoneksikan berbagai konsep matematika yang mereka pelajari (Handayani, 2019).

Matematika merupakan mata pelajaran yang terurut, bertingkat dan berkelanjutan. Artinya materi yang diberikan kepada siswa adalah konsep-konsep dasar yang merupakan fondasi dalam penyampaian konsep selanjutnya (Qadarsih, 2017). Keberhasilan penguasaan konsep awal matematika pada siswa merupakan pembuka jalan dalam penyampaian konsep-konsep matematika selanjutnya. Siswa akan lebih mudah dalam memahami konsep-konsep matematika pada materi-materi selanjutnya. Oleh karena itu, koneksi matematis merupakan kemampuan yang penting untuk dikuasai oleh siswa. Apabila siswa menguasai konsep dengan baik maka siswa dapat menyelesaikan berbagai variasi soal matematika dan dapat mempermudah siswa dalam menyelesaikan masalah matematika yang berkaitan dengan kehidupan sehari-hari.

Berdasarkan uraian tersebut, penelitian ini bertujuan untuk: a) untuk mengetahui prosentase soal Ujian Sekolah yang memenuhi kriteria koneksi matematis, b) mengetahui contoh soal Ujian Sekolah yang memenuhi kriteria koneksi matematis.

\section{METODE PENELITIAN}

Penelitian ini adalah penelitian kualitatif dengan metode analisis isi (content analysis). Metode ini dipilih karena dalam penelitian ini akan melakukan penelitian pada dokumen/pustaka yang berupa butir soal dalam ujian sekolah/madrasah SMP/MTs matematika tahun 2018/2019. Penelitian ini akan menganalisis butir soal ujian sekolah SMP/MTs provinsi Jawa Timur tahun ajaran 2018/2019 berdasarkan kriteria koneksi matematis. Prosedur penelitian ini adalah sebagai berikut : (1) Persiapan, yaitu mengidentifikasi dan merumuskan masalah yang diteliti (2) Pelaksanaan, yaitu pengumpulan data, analisis dan interpretasi data (3) Tahap akhir yaitu penyusunan laporan penelitian dan menyusun artikel. 


\section{Efektor, Volume 7 Issue 1, 2020, Pages 73 - 79 \\ Habib Hasbullah}

\section{HASIL DAN PEMBAHASAN}

Dari hasil analisis yang dilakukan dengan mengambil satu jenis Soal Ujian Nasional Matematika SMP/MTs tahun 208/2019 diperoleh hasil bahwa dari 40 soal yang diujikan, sebanyak 32 soal memenuhi kriteria sebagai soal memuat indikator koneksi matematis. Dari jumlah tersebut, apabila diprosentase, maka dapat dikatakan sebanyak $80 \%$ soal merupakan soal koneksi matematis sedangkan $20 \%$ soal lainnya dapat dikerjakan tanpa harus mengetahui koneksi konsep matematika tersebut dengan konsep lain, dengan bidang lain, maupun juga dengan kehidupan sehari-hari. Apabila digambarkan dalam diagram lingkaran, hasil tersebut dapat disajikan dalam Gambar 1 berikut:

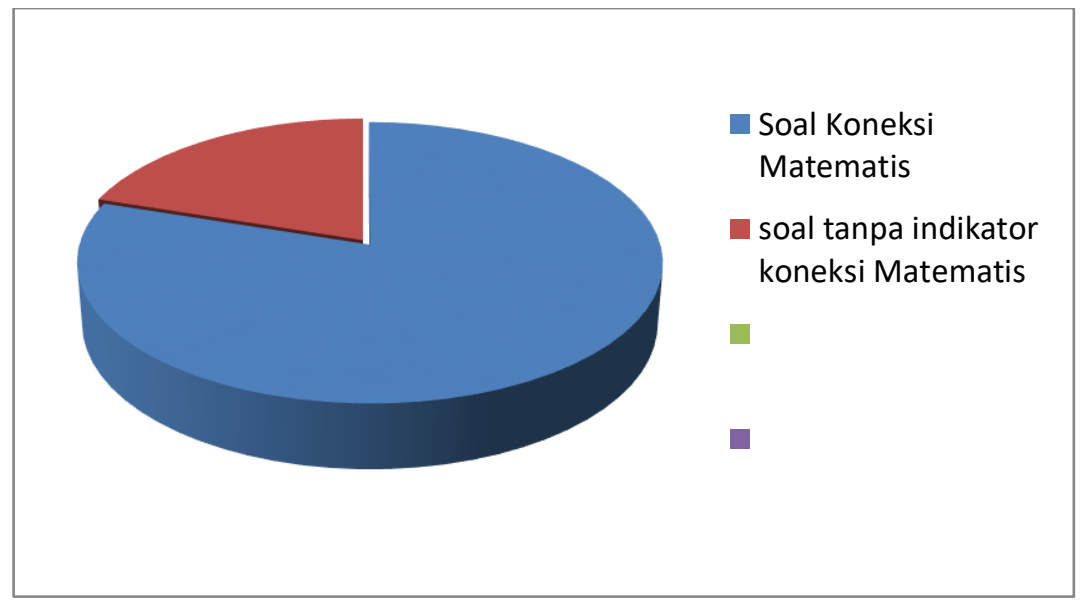

Gambar 1 Diagram banyaknya soal Koneksi Matematis pada Soal UN Matematika SMP.MTs Tahun 2018/2019.

Dari Gambar 1 terlihat bahwa 80\% soal yang diujikan pada Ujian Nasional Matematika SMP/MTs memenuhi kriteria koneksi matematis. Hal ini meuntut siswa setingkat SMP/MTs untuk menguasai keterampilan koneksi matematis. Sebagaimana pendapat Sumarmo (2013), siswa hendaknya memahami konteks antar ide-ide matematika dan antara matematika dengan bidang ilmu lainnya. Apabila dikaitkan dengan hasil analisis butir soal koneksi matematis yang disajikan dalam Soal Ujian Nasional SMP/MTs, maka hal tersebut juga menunjukkan bahwa kemampuan koneksi merupakan kemampuan yang wajib dimiliki siswa yang belajar matematika di tingkat SMP sederajat. Sehingga guru juga hendaknya berupaya untuk memberikan pengalaman belajar siswa untuk meningkatkan kemampuan koneksi matematisnya.

Apabila ditinjau dari indikator masing-masing kriteria koneksi matematis, dari total 32 soal koneksi matematis, 12 soal diantaranya termasuk dalam soal yang mewakili indikator keterkaitan antar konsep dalam matematika, 6 soal termasuk dalam soal yang mewakili indikator keterkaitan antara konsep matematika dengan bidang lain dan 14 soal lainnya merupakan soal yang memuat keterkaitan antara konsep matematika dengan kehiduoan sehari-hari. Berikut prosentase dari ketiga indikator soal koneksi matematis disajikan dalam Gambar 2. 


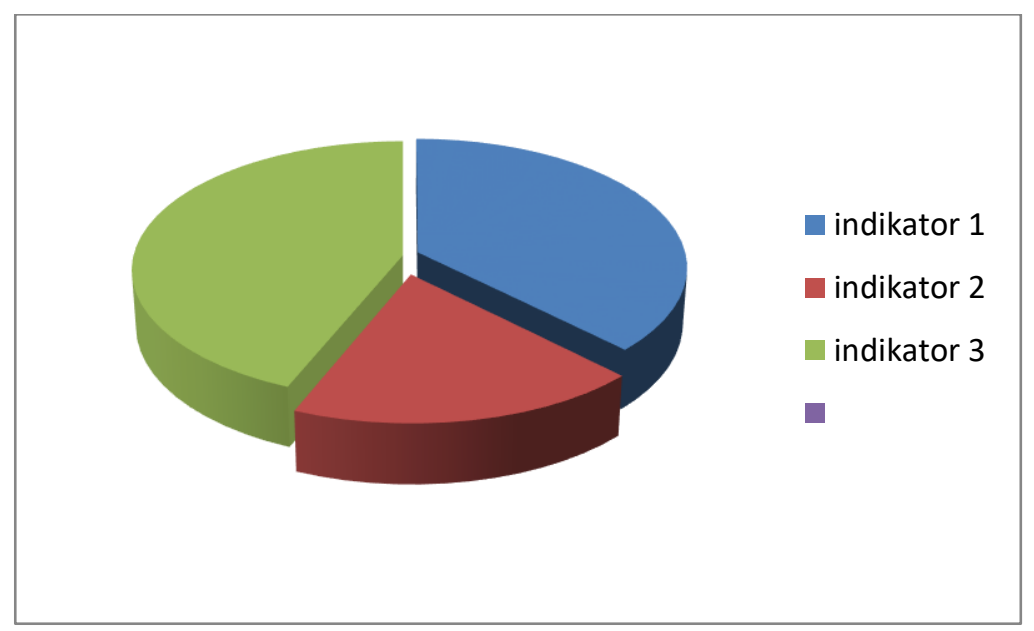

Gambar 2. Digaram perbandingan banyaknya soal berdasarkan ketiga indikator koneksi matematis

Berdasarkan Gambar 2, dari 32 soal yang memenuhi kriteria koneksi matematis, 37,5\% termasuk dalam indikator koneksi matematis yang pertama, yaitu mengetahui koneksi antar konsep dalam matematika, 18,75\% termasuk dalam indikator koneksi matemtis yang keduan yaitu mengetahui hubungan antara konsep matematika dengan bidang lain. Sedangkan $43,75 \%$ soal lainnya termasuk dalam indikator koneksi matematis yang ke tiga yaitu mengetahui hubungan atau penerapan konsep matematika dengan bidang lain. Dari ketiga indikator koneksi matematis, prosentase terbanyak soal koneksi matematis adalah soal yang memuat keterkaitan antara konsep matematika dengan materi kehidupan sehari-hari. Hal ini juga menunjukkan pentingnya matematika dalam kehidupan sehari-hari. Sedangkan keterkaitan matematika dengan bidang ilmu lain antara lain adalah konsep prosentase untuk menghitung bunga tabungan (bidang perbankan), konsep skala untuk menghitung ukurang gedung (bidang sipil), keterkaitan antara konsep perpangkatan untuk menghitung banyaknya bakteri (bidang biologi) dan keterkaitan antara konsep matematika dengan statistika. Mengingat keterkaitan antar konsep dalam matematika, antara konsep matematika dengan bidang ilmu lain maupun antara konsep matematika dengan kehidupan sehari-hari merupakan bagian yang penting dari kurikulum matematika sekolah, maka dalam belajar matematika, siswa harus mendapat kesempatan untuk mendapatkan pengalaman belajar tentang koneksi matematis.

Matematika bukan koleksi konsep yang terpisah-pisah, meskipun sering dipartisi dan disajikan secara terpisah antara konsep satu dengan konsep lainnya. Sebaliknya, matematika adalah bidang studi yang terintegrasi. Ketika siswa menghubungkan matematika ide, pemahaman mereka lebih dalam dan terekam lebih lama dalam ingatan sehingga siswa dapat untuk melihat matematika sebagai keseluruhan yang koheren. Melalui kemampuan koneksi matematis, siswa dapat mengetahui interaksi antara topik matematika, dalam konteks yang terkait dengan matematika mata pelajaran lain, dan untuk minat dan pengalaman mereka sendiri. Melalui pembelajaran yang menekankan keterkaitan ide matematika, siswa belajar tidak hanya matematika tetapi juga tentang kegunaan matematika (NCTM, 2000) 


\section{Efektor, Volume 7 Issue 1, 2020, Pages 73 - 79 \\ Habib Hasbullah}

Penelitian Badjeber (2015) menunjukkan bahwa Peningkatan kemampuan koneksi matematis siswa yang diajar dengan pembelajaran inkuiri model Alberta lebih baik secara signifikan daripada siswa yang diajar dengan menggunakan metode konvensional. Hal ini menunjukkan bahwa guru hendaknya memfasilitasi siswa untuk meningkatkan kemampuan koneksi matematisnya dengan melaksanakan pembelajaran yang menjadikan pembelajaran berpusat pada siswa, tidak hanya monoton dengan pembelajaran konvensional. Hal ini juga selaras dengan Toh (2012), yang menyatakan bahwa tujan matematika sekolah adalah: 1) memperoleh konsep dan keterampilan matematika yang diperlukan dalam kehidupan sehari-hari dan pembelajaran yang kontinu dalam matematika dan disiplin ilmu yang terkait, 2) mengenali dan menggunakan ide-ide dalam matematika dan antara matematika dan disiplin ilmu yang lainnya.

Dalam pembahasan berikutnya disajikan beberapa contoh soal UN SMP/MTs tahun 2018/2019 yang menuntut siswa untuk menguasai kemampuan koneksi matematis:

a. Keterkaitan antar konsep dalam matematika

1. menentukan diagonal ruang sebuah balok.

untuk menentukan diagonal ruang sebuah balok pada gambar yang diberikan diperlukan kemampuan siswa untuk mengerti tentang konsep phytagoras)

2. menentukan dua garis sejajar.

pada soal ini disajikan beberapa persamaan garis. Untuk dapat menentukan dua grais sejajar, terlebih dahulu siswa harus dapat menentukan gradien masing-masing garis.

3. menentukan pasangan sudut yang sama besar dari dua segitiga yang kongruen

untuk menjawab soal ini, siswa harus memahami tentang konsep bangun yang kongruen dan pasangan garis dan sudut yang berukuran sama

4. menentukan panjang busur suatu lingkaran

untuk dapat menghitung panjang bsusur suatu lingkaran, siswa harus paham tentang cara menghitung perbandingan

5. menentukan besar sudut suatu segitiga apabila diketahui ketiga sudutnya dalam variabel tertentu konsep awal yang harus dimiliki siswa untuk menjawab pertanyaan ini adalah konsep penjumlahan variabel dalam aljabar

6. menentukan volume limas persegi apabila diketahui keliling alas dan tinggi

sebelum menentukan volume limas, siswa harus menghitung panjang sisi persegi yang bisa diperoleh dari luas persegi yang diberikan

7. menentukan volume tabung apabila diketahui panjang jari-jari dan tinggi limas untuk menghitung volume tabung, siswa terlebih dahulu harus menghitung luas alas tabung (luas lingkaran) 


\section{Efektor, Volume 7 Issue 1, 2020, Pages 73 - 79 \\ Habib Hasbullah}

b. Keterkaitan antara konsep matematika dengan bidang ilmu lain

1. menentukan banyaknya pekerja agar pekerjaan selesai sesuai waktu yang ditentukan (kaitan antara konsep perbadingan dengan bidang teknik sipil)

2. menentukan ukuran gedung sebenarnya apabila diketahui skala pada denah (kaitan antara kosep skala dengan bidang teknik sipil)

3. menentukan banyaknya tabungan (kaitan antara konsep prosentase bunga dengan bidang perbankan)

4. menentukan skala apabila diketahui ukuran sebenarnya dengan ukuran pada gambar kaitan antara kosep skala dengan bidang teknik sipil)

5. menentukan waktu yang diperlukan bakteri sehingga membelah diri menjadi jumlah yang ditentukan (kaitan antara konsep bilangan berpangkat dengan bidang biologi)

6. menentukan banyaknya orang berdasarkan data yang disajikan dalam diagram lingkaran (kaitan antara konsep statistika dengan bidang kependudukan)

c. Keterkaitan konsep matematika dengan kehidupan sehari-hari

1. menentukan skor total apabila diketahui skor untuk jawaban salah, jawaban benar dan tidak dijawab serta jumlah soal (konsep operasi bilangan)

2. menentukan beberapa hari berikutnya jika diketahui hari dan tanggal yang ditentukan (konsep kelipatan persekutuan terkecil)

3. menentukan banyaknya benda apabila diketahui perbandingan dan jumlah keseluruhan benda tersebut (konsep perbandingan)

4. menentukan banyaknya siswa yang terpilih sebagai pengurus OSIS apabila diketahui banyaknya pendaftar, banyaknya siswa yang lulus tes tulis, banyaknya siswa yang lulus tes wawancara dan banyaknya siswa yang tidak mengikuti seleksi (konsep diagram Venn)

5. menentukan harga sepatu yang harus dibayar jika diketahui harga 2 pasang sepatu dan 3 pasang sandal dan harga 3 pasang sepatu dan 2 pasang sandal (konsep Sistem Persamaan Linear Dua Variabel)

6. menentukan banyaknya pendapatan uang parkir apabila diketahui jumlah roda kendaraan keseluruhan dan total banyaknya kendaraan serta tarif parkir masing-masing kendaraan (konsep Sistem Persamaan Linear Dua Variabel)

7. menentukan luas taman yang ditengahnya terdapat kolam (konsep luas bangun datar)

8. menentukan tinggi gedung berdasarkan sketsa yang diberikan (konsep segititiga sebangun)

\section{SIMPULAN}

Dari berbagai uraian tersebut disimpulkan bahwa dari analisis butir soal yang dilakukan terhadap soal Ujian Nasional Matematika SMP/MTs tahun 2018/2020, sebanyak 80\% merupakan soal koneksi matematis. Dari keseluruhan soal koneksi matematis, 37,5\% merupakan soal yang memuat keterkaitan antar konsep dalam matematika, 18,75\% merupakan soal yang memuat keterkaitan antara konsep matematika dengan bidang lain dan 
Efektor, Volume 7 Issue 1, 2020, Pages 73 - 79

Habib Hasbullah

sebagian besar yaitu sebanyak $43,75 \%$ merupakan soal yang memuat keterkaitan antara konsep matematika dengan bidang lain

\section{DAFTAR RUJUKAN}

Badjeber, R dan Fatimah, S. 2015. Peningkatan Kemampuan Koneksi Matematis Siswa Smp Melalui Pembelajaran Inkuiri Model Alberta. Jurnal Pengajaran MIPA Vol 20 No 1 Tahun 2015 hal 18-27

Qadarsih, N.D. 2017. Pengaruh Kebiasaan Pikiran (Habits Of Mind) Terhadap Penguasaan Konsep Matematika. Jurnal SAP Vol. 2 No. 2 Desember 2017 p-ISSN: 2527-967X e-ISSN: 2549-2845. Indonesia: Universitas Indraprasta PGRI

Handayani, A.D., Herman, T., Fatimah, S., Setyowidodo, I. 2019. Enhancing Mathematical Connection ability of Mathematics Education student Through Inquiry based Learning. Journal of Physics Conference Series. Online. Tersedia : https://iopscience.iop.org/article/10.1088/1742-6596/1280/4/042028/pdf

NCTM. 2000. Principles and Standard for School Mathematis - NCTM. Artikel Online. Tersedia: https://www.nctm.org/uploadedFiles/Standards_and_Positions/PSSM_ExecutiveSummary.pdf

NCATE/NCTM Program Standards (2003). Programs for Initial Preparation of Mathematics Teachers. Online. Tersedia: http://www.math.uri.edu/ eaton/NCATENCTM.pdf

Niss, Mogens. 2011. Mathematical Competencies and the Learning Of Mathematics: The Danish Kom Project Imfufa. Roskilde University. Online. Tersedia: http://www.math.chalmers.se/Math/Grundutb/CTH/mve375/1213/docs/KOMkompetenser.pdf

Sumarmo, Utari. (2016). Pedoman pemberian Skor pada beragam Tes Kemampuan Matematik. Kelengkapan Bahan Ajar Mata Kuliah Evaluasi Pembelajaran Matematika pada Program Magister Pendidikan Matematika STKIP Siliwangi handung http://utarisumarmo.dosen.stkipsiliwangi.ac.id/files/2016/05/Pedoman-Pemberian-Skor-Tes-Kemampuan-BerpikirMatematik-dan-MPP-2016-1.pdf 